\title{
Glossopharyngeal Sulcus
}

National Cancer Institute

\section{Source}

National Cancer Institute. Glossopharyngeal Sulcus. NCI Thesaurus. Code C105407.

A groove between the base of the tongue and the palatine tonsil. 